\title{
Personalized pricing in the digital era
}

\section{Alex Schofield*}

\begin{abstract}
Personalized pricing can have negative or positive effects for consumers. Concerns are more likely to arise in circumstances where there is limited competition, or where consumers are unaware of, do not understand, and/or cannot avoid personalization. In some circumstances, personalization may be unfair or otherwise illegal under the Consumer Protection from Unfair Trading Regulations 2008 or other legislation. It may also distort competition and give rise to consumer harm and thereby infringe UK or EU competition law, or cause markets to not work effectively and therefore justify a market study or investigation by the Competition and Markets Authority ('CMA') under the Enterprise Act 2002. This article considers how the CMA will tackle personalized pricing that may distort competition in digital markets.
\end{abstract}

Keywords: personalized pricing, price discrimination, digital markets, algorithms, Competition and Markets Authority, Competition Act 1998

\section{Executive summary}

Personalized pricing can have negative or positive effects for consumers. Concerns are more likely to arise in circumstances where there is limited competition, or where consumers are unaware of, do not understand, and/or cannot avoid personalization. Concerns will also arise where personalization is based on particular characteristics of the individual consumer that may be associated with vulnerability - such targeting may be unfair, or illegal (if based on protected characteristics). Online markets increase the scope for personalization and, unlike markets offline, allow for traders to collect information about a consumer's search behaviour without the consumer being able to see the pricing offers made to other consumers.

Where personalization takes place, it is less likely to be harmful where consumers know it is happening, understand how it works and can exercise effective choice. Transparency alone will not necessarily adequately address the risk of consumer harm, and the quality of disclosure is vital. The disclosure of information on personalization will serve little positive purpose if the information provided to the consumer is misleading, confusing or otherwise not comprehensible to the consumer and/or does not give the consumer a real choice (e.g. the disclosure is made very late in the transactional process).

Furthermore, the nature of personalization and the claims made as a result of the personalization can be a misleading, deceptive or an otherwise unfair practice in some circumstances. UK consumer protection legislation ${ }^{1}$ protects consumers from commercial practices that are considered unfair, misleading actions, misleading omissions and commercial practices that are aggressive.

The Competition and Markets Authority ('CMA') will use its full range of powers to tackle harm in digital markets, whether individually or in combination, ${ }^{2}$ focusing on using the best tool to address the potential concern. Personalized pricing can potentially distort competition and subsequently breach the Chapter II prohibition of the Competition Act 1998 in circumstances where online traders abuse dominant positions by using algorithms determining the consumer's maximum willingness to pay. Given ambiguous effects, the CMA would undertake
Strategy and EU Exit Lead, Ministry of Justice, London; formerly Policy Specialist, Competition and Markets Authority, London. This article is based upon a submission made by the Competition and Markets Authority to a best practice roundtable organized by the Competition Committee and the Committee on Consumer Policy of the Organisation for Economic Co-operation and Development held on 28 November 2018, full details of which are available at: http://www.oecd.org/daf/competition/personalisedpricing-in-the-digital-era.htm.

1 E.g. the Consumer Protection from Unfair Trading Regulations 2008, SI 2008/1277 ('CPR 2008'). See CPR 2008, Part 2, regulation 6 for further details of the provisions for misleading omissions.
2 For example, following a market study into digital comparison tools ('DCTs') using powers under the Enterprise Act 2002, the CMA made recommendations to DCT providers to help online traders comply with the law (see CMA, Digital comparison tools market study, Final Report (29 September 2018)), but separately opened a competition law investigation into a specific provider (see CMA press release, ComparetheMarket insurance deals could deny people better prices (2 November 2018)). 
an evidence-based assessment of the market and consider carefully the best form (if any) of intervention in a case at hand. This includes recognizing the risks of both inaction and significant interventions.

The CMA, and previously the Office of Fair Trading ('OFT'), has published guidance for businesses, including recommendations from its previous studies into digital markets to help online traders comply with consumer and competition law and to support effective growth of digital markets.

\section{The nature and prevalence of personalized pricing}

For the purposes of this article, we use the term 'personalized pricing' to describe the use by businesses of information that is observed, volunteered, inferred or collected about individuals' conduct or characteristics, to set different prices to different consumers (whether on an individual or group basis), based on how price sensitive the business perceives them to be.

Personalized pricing is - as the CMA's predecessor, the OFT, put it in its 2013 report $^{3}$ - a 'relatively refined' form of the broader practice of direct price discrimination or differentiated pricing. ${ }^{4}$ For present purposes, we also exclude differences in price that result from genuine differences in the costs to the business of serving a particular customer (e.g. increased shipping costs for overseas jurisdictions).

\subsection{How prevalent is personalized pricing?}

The prices of certain goods and services, such as insurance, are by their nature personalized, based on, in that case, a consumer's particular risk profile. Looking more broadly, it has long been possible for businesses to personalize prices using a few observable customer characteristics (e.g. 'third-degree' price discrimination, such as student discounts) or by providing options that induce customers to self-select different effective prices (e.g. 'second-degree price discrimination', such as quantity discounts).

However, the increasing availability of data and use of sophisticated pricing algorithms to swiftly analyse this data and gather granular intelligence about customers' preferences, purchases or price sensitivity, raises the possibility that traders - and particularly those trading online - may be able to engage in highly personalized pricing, effectively sorting customers into ever smaller and more refined categories. ${ }^{5}$

In the extreme, the outcomes of highly personalized pricing may approach those of perfect, or 'first-degree', price discrimination, in which every customer is offered an individual price based on that consumer's price sensitivity or willingness to pay. We discuss later the implications for consumers - and well-functioning markets more generally - of this evolution.

The CMA has recently published a review ${ }^{6}$ that analyses the evidence on how consumers search online and how firms operate as a result of this behaviour. As noted in the research, past studies (principally based on markets in the US) have found some evidence of businesses offering different prices to different consumers. As part of this research, the CMA expanded on past experiments in the UK, and compared the prices of a selection of varied products, across different operating systems, when accessed directly or through an affiliate website (e.g. a digital comparison tool or cashback site), and against logged in customer profiles, to determine if there was any evidence of personalized pricing.

The research found no material evidence of pricing ${ }^{7}$ being different or personalized for different consumers. These findings were largely mirrored in a larger study subsequently undertaken by the European Commission, ${ }^{8}$ in which price differences were only observed in $6 \%$ of tests, and the median price difference observed was less than $1.6 \%$.

3 OFT, The Economics of Online Personalised Pricing (May 2013), available at: https://webarchive.nationalarchives.gov.uk/20140402154756/http:/oft. gov.uk/shared_oft/research/oft1488.pdf.

4 Personalized pricing, as so defined, is distinct from, for example, dynamic pricing. While the latter equally involves adjusting prices to reflect anticipated consumer willingness to pay, with dynamic pricing, variables are not customer related, and so all customers on a site see the same price at the same time. Traders typically use dynamic pricing to manage (and maximize revenue from) temporal variations in demand for products or services, or fluctuations in their competitors' prices and availability. However, as we discuss further below, businesses may use personalized and dynamic pricing in combination.

5 Businesses may use this data to personalize offers to specific customers in ways other than through differentiated pricing. For example, different customers may see available products ranked or displayed in a different way or have the advertising on a site adjusted based upon the data collected from them. While such practices may give rise to competition or consumer protection concerns (see e.g. the CMA's ongoing investigation into the online hotel booking sector: the case timetable is available at:

https://www.gov.uk/cma-cases/online-hotel-booking; and see CMA press release, CMA launches enforcement action against hotel booking sites (28 June 2018)), they are not the focus of this article.

6 CMA, Pricing algorithms: Economic working paper on the use of algorithms to facilitate collusion and personalised pricing (CMA94, 8 October 2018), available at: https://assets.publishing.service.gov.uk/government/uploads/ system/uploads/attachment_data/file/746353/Algorithms_econ_report.pdf.

7 There were, however, examples of different consumers being shown different search results on retail websites, including different numbers of results or a different order of results. As noted above, such practices could potentially have effects on competition or consumers, but are not the focus of this article.

8 European Commission, Directorate-General for Justice and Consumers, Consumer market study on online market segmentation through personalised pricing/offers in the European Union, Final Report (June 2018), available at: https://ec.europa.eu/info/sites/info/files/aid_development_ cooperation_fundamental_rights/aid_and_development_by_topic/docu ments/synthesis_report_online_personalisation_study_final_0.pdf. 
It should be noted, however, that the CMA's analysis, which was limited in scope and scale, focused on varying one factor at a time: given the wide range of potentially relevant factors (which can interact), more sophisticated methods may be necessary to definitively identify the scale and nature of any personalization in these markets. Such methods would, for example, enable the profile of a user accumulated over time to be taken into account, and any effect therefrom to be excluded from the analysis.

Furthermore, the research cited above considered only 'headline', displayed prices. Businesses may personalize prices in other ways, for example by sending certain customers unique discounts by email.

\section{The potential effects of personalized pricing on competition and consumers}

Using an economic perspective, most forms of personalized pricing are underpinned by a combination of the four key effects set out below: ${ }^{9}$

- The appropriation effect: Personalized pricing can allow firms to charge higher prices to consumers with less sensitivity to price, meaning that the firm is better off and the consumers with less sensitivity to price are worse off.

- The output expansion effect: Personalized pricing can allow firms to charge a lower price to consumers with higher sensitivity to price, meaning that more of them would buy compared to under a uniform price. This expands the output sold.

- The intensified competition effect: The effects of personalized pricing on competition are complex, but one possibility is that it can trigger increased competition between competing firms, as each firm is better able to target customers of other firms with a competitive price offer.

- The commitment effect: Personalized pricing can prevent firms from committing not to decrease their prices in the future.

However, the overall effect on competition and consumers of a given case of personalized pricing is ambiguous, and will depend not only on how those four effects balance out against each other, but also on a range of case-specific factors, including, for example, (i) the intensity of competition in the market, (ii) the complexity of price personalization (and thus how likely consumers are to understand it) and (iii) the cost to the firm of personalizing offers:

- For example, personalization based on consumers' data (e.g. their previous purchases or past searches) can mean that consumers receive offers that better suit their individual needs or circumstances, including through targeted discounts on products likely to be of interest. Personalized offers may also give consumers useful information about a product in which they are interested rather than simply presenting different pricing. As such, personalized offers can give consumers access to new products and help consumers identify the most suitable products for a better price than they would otherwise achieve through uniform pricing.

- In some markets, personalization can incentivize (or 'nudge') consumers to make healthier or better lifestyle choices, in order to access lower prices. ${ }^{10}$

- While personalized pricing means that there will be consumers who gain relative to uniform pricing, there will be others who may 'lose' and pay more than they would in a uniform pricing scenario. This may be regarded as a positive outcome, where those paying less are, for example, vulnerable consumers on a low income, or those who would otherwise not be able to access a market. However, those paying more or less will often be differentiated on other grounds, which have little to do with (or may be negatively correlated with) their ability to pay. For example, personalization often means that active and engaged consumers benefit at the expense of inactive, longstanding or disengaged consumers, ${ }^{11}$ or that the 'digitally savvy' can access lower prices than those who are unable to access online services, for financial, technological literacy or other reasons.

- In the extreme, personalization can in principle result in differentiated prices being set at the highest price because the business considers that a given consumer is, from their data 'profile', likely and willing to pay. Even where this increases overall output, insofar as it means that much (potentially,
9 See OFT, The Economics of Online Personalised Pricing (fn 3). As the CMA submission to the OECD Roundtable on Algorithms and Collusion (June 2017) (available at: https://one.oecd.org/document/DAF/COMP/WD (2017)19/en/pdf and republished as S. Constantine and V. Quitaz, OECD Competition Committee Best Practice Roundtable - algorithms and collusion: United Kingdom submission [2018] Comp Law 41) highlights, algorithmic price personalization will typically reduce the scope for (and indeed generally be mutually exclusive with) the use of algorithms to collude on prices. That is, price discrimination is typically the result of unilateral conduct by a single firm, and results in multiple prices, in contrast with the 'single' or 'agreed' price that results where companies collude.
10 For example, in some markets, personalized pricing could be used as a behavioural nudge to improve overall consumer welfare, whether by encouraging consumers to drive more carefully (e.g. through telemetrics-linked motor insurance premiums), improve their fitness (to access lower health insurance rates) or reduce waste (e.g. reduced prices for those using their own cup in a coffee shop, rather than single-use cups).

11 For example, because firms use personalization to 'target' competitors' customers whom they feel are likely to switch. 
all) of the economic surplus is rerouted from the consumer to the trader, it is likely to result in materially worse outcomes for consumers and erode consumer trust in online markets.

- As the digital economy grows, the intensification of this practice and the ability for online traders to collect consumer data or use algorithms is liable to widen the gap between those that benefit and those that are potentially harmed from personalized offers.

A case-by-case assessment is therefore necessary in order to determine the effects and the possible benefits or harms to consumers in any given personalization scenario, including the extent to which vulnerable consumers have been harmed.

\subsection{When are concerns more likely to arise?}

As alluded to above, the level of competition in a market can be a key indicator of whether personalized pricing risks harming competition and consumers.

For example, where there is no effective competition between firms in a market (i.e. in monopolized markets), a monopolist may be able to use targeted differential pricing anti-competitively in order to exclude competitors or raise barriers to new entry (e.g. by engaging in predatory behaviour through selective discounts). Similarly, in markets characterized by consumer inertia in switching (e.g. where consumers 'single home' ${ }^{\text {'12 }}$ on a particular price comparison website or online marketplace), firms can use personalization to identify and exploit - through higher prices - their inactive or 'sticky' customer base.

Although personalization of prices in markets where competition does exist may be neutral or positive for consumers (as the possibility and threat of consumer switching will discipline firms not to act against consumers' interests), even in those circumstances, concerns may arise. In particular, personalization in even a competitive market is more likely to be harmful where one or more of the following factors is present.

- Consumers cannot easily avoid personalization if they wish to (including because a particular good or service is an 'essential' rather than a discretionary purchase), or it is not clear to them how to take control and use personal data to inform their purchasing decisions. ${ }^{13}$

- The form of price discrimination is particularly complex or opaque to consumers. Consumers may, for example, be unaware that the price for a given product displayed to them is different from the price displayed to another consumer or - even if they are aware - may have little understanding of how that price was determined. This may reduce the ability of customers to identify a baseline price for a product and thus make it more difficult for them to make fully informed buying decisions or to act as a 'discipline' on firm behaviours (and thereby drive competition). This may be a particular issue when personalization is combined with dynamic pricing, and risks damaging consumer trust in online markets more generally.

- Firms have the ability and incentive to exploit consumer behavioural biases and thus to inhibit consumers' ability to make economically rational transactional decisions in response to personalized pricing. ${ }^{14}$

- The groups disadvantaged by price discrimination are considered vulnerable.

- It is very costly for firms to implement and firms are likely to pass on these higher costs to consumers in the form of higher prices overall.

We consider some of these aspects in further detail below.

\subsection{The role of transparency}

As noted above, where personalization takes place, it is less likely to be harmful where consumers know it is happening and understand how it works. Transparency can also help more broadly to sustain consumer trust in markets. As such, the CMA regards transparency as a core part of businesses minimizing the risk that their pricing practices do not breach competition or consumer law.

However, mere transparency alone will not necessarily adequately address the risk of consumer harm. It is equally the quality of disclosure that is vital - disclosure of information on personalization will serve little positive purpose if the information provided to the consumer is misleading, confusing or otherwise not comprehensible to the consumer, and/or does not give them a real choice (e.g. the disclosure is made very late in the transactional process).
12 Meaning that consumers only ever use one price-comparison website.

13 The European Commission DG Justice and Consumer report, Consumer market study on online market segmentation through personalised pricing/offers in the $E U$ (fn 8), found that consumers would be more positive about personalization if they received more information and had more control over these practices. From the study, six in ten online respondents (from $28 \mathrm{EU}$ Member States) reported that they would be more positive if there was an easy option to refuse.
14 Such biases may include the fact that, for example: consumers disproportionately choose default options, and care more about losses than gains (and thus will tend to maintain the status quo); consumers can easily become overwhelmed by information (making decision-making more difficult and dissuading them from switching); consumers anchor headline prices and are bad at anticipating/assessing future needs (and thus may be susceptible to drip pricing, or high 'aftermarket' costs). 
The effectiveness of transparency in protecting consumers may also be inhibited by consumer behaviours: many consumers do not read information notices or would not act on these notices even if they did read them, particularly during online transactions. Indeed, recent behavioural experiments exploring how people respond to low transparency/high transparency websites ${ }^{15}$ suggests that transparency had no statistically significant effect on whether or not people bought a product.

As such, the CMA considers that effective transparency is a necessary but not sufficient condition to ensure that personalized pricing practices do not risk violating the law.

\subsection{Personalization and trust in online markets}

Many of the market characteristics described above and which make personalized pricing more likely to be harmful apply to online retailing more than they do to offline retailing. In particular:

- Online retailing is (i) more likely to be complex, as firms can observe with far greater specificity minor differences in consumer behaviours, and (ii) more likely to be opaque, as consumers may not be able to observe the price being quoted to other consumers, irrespective of whether almost all consumers receive some form of a discount or the extent to which prices are dynamic.

- In online markets, consumers often cannot easily avoid personalization if they wish to. For example, many websites require customers to sign-in before placing an order, and personalization may be based on factors such as an IP (transmission control proto$\mathrm{col} /$ internet protocol) address, browser type or device used by the consumer.

A key concern for the CMA - from both a competition and consumer protection perspective - is the risk that systematic price discrimination (particularly where it is perceived to be complex or secretive or to discriminate 'unfairly' against certain categories of consumer) may undermine consumer trust in online markets, and cause consumers to disengage from them. That loss of trust may occur not only in relation to those companies undertaking such personalization, but in relation to online commerce more generally.

Consumer trust is vital for markets to function effectively. ${ }^{16}$ As well as limiting opportunities for new online entry, a loss of trust may also result in certain customers

15 Consumer market study on online market segmentation through personalised pricing/offers in the European Union (fn 8), section 6.

16 See W. Hall and J. Peseneti, Growing the Artificial Intelligence Industry in the UK (October 2017) (available at: https://www.gov.uk/government/ publications/growing-the-artificial-intelligence-industry-in-the-uk), which noted a growing consensus that decisions based on data analysis and which affect people should be fair and should be demonstrably fair. It (e.g. those with low levels of digital literacy) being deterred from transacting online, and thus from access to the full range of offers, and to any lower prices that are offered only to online customers (whether by their existing supplier or its rivals). Furthermore, consumers will find it more difficult to compare prices.

An overview of key factors determining a consumer and a trader reaction to personalized pricing is included in Annex 1.

\section{The legal assessment of personalized pricing and the CMA's approach}

\subsection{Personalized pricing under competition and consumer protection law}

UK laws place certain limits on personalized pricing where they may result in harm to competition or consumers. For example:

- Consumer protection law: personalized pricing may breach the CPR 2008 if it is misleading, or if the underlying data about the consumer was obtained unlawfully (e.g. without their valid, freely given, specific, informed and active consent, contrary to data protection laws). An outline of the CPR 2008 and its provisions relevant to personalized pricing is included in Annex 2.

- Competition law: an undertaking in a dominant position could contravene UK or EU unilateral conduct laws ${ }^{17}$ if it uses personalized pricing to exploit customers (e.g. by charging excessively high prices to those customers unable to switch) or to exclude rivals (e.g. by using high prices to 'trapped' customers to subsidize very low prices to customers more susceptible to competition from new rivals, thus inhibiting new market entry).

As noted above, however, given that personalization can have either positive or harmful effects for competition and consumers, a case-by-case assessment of the conduct in its particular context will be required in determining if and how such laws apply.

\subsection{Other laws relevant to personalized pricing}

This article focuses on the CMA's use of consumer and competition powers. We note for completeness, however,

referred to the recommendation of the Royal Society and British Academy which sets out a principle for data governance to 'ensure that trade-offs affected by data management and data use are made transparently, accountably and inclusively'. Recommendation 14 of the authors' report suggested a framework for explaining processes, services and decisions delivered by AI, to improve transparency and accountability.

17 Chapter II of the Competition Act 1998 or Article 102 TFEU. 
that there are other laws - not enforced primarily by the CMA - with which businesses active in the UK must also comply and which may equally prohibit or limit certain forms of price discrimination. These include, for example:

- Equalities legislation, which prohibits, with a few exceptions, discrimination on the basis of protected characteristics such as age, disability, pregnancy, gender or sexuality, marital status, race or religion.

- Data protection legislation, ${ }^{18}$ which requires, for example, that consumers provide informed consent to certain forms of data gathering, that they are informed when an automated decision is made about them, etc.

- Laws restricting online retailers' ability to offer different terms (not justified by objective cost differentials) for providing the same service to consumers based on their location.

- Advertising and marketing laws, which, for example, regulate (and require transparency over) online behavioural advertising, that is, advertising customized on the basis of a user's data. ${ }^{19}$

\subsection{The CMA's approach to intervention}

The CMA's overarching objective is to make markets work well, both for consumers and businesses. Within that, and as reflected in its 2018-2019 Annual Plan, ${ }^{20}$ the CMA's particular areas of strategic focus in its selection of cases include vulnerable consumers, ensuring markets can be trusted, and online and digital markets.

As in all of its work, the CMA will use its full range of powers to tackle harm in digital markets, whether individually or in combination, ${ }^{21}$ focusing on using the best tool to address the potential concern. This includes not only its mergers, ex post and ex ante competition and consumer enforcement powers, but also its market investigation powers, which enable it to investigate and if necessary address - features of a market (or across markets) that may be adversely affecting competition. In deciding whether to intervene, the CMA will apply its published Prioritisation Principles, ${ }^{22}$ taking into account the likely harm of the conduct to consumers, or certain groups of consumers (e.g. vulnerable consumers).

18 In particular the Data Protection Act 2018, which implements in the UK Regulation (EU) No 2016/679 on the protection of natural persons with regard to the processing of personal data and on the free movement of such data ('General Data Protection Regulation'), OJ 2016 L 119/1.

19 See Advertising Standards Authority ('ASA'), Guidance on Online Behavioural Advertising (OBA) (4 January 2016), available at: https://www.asa. org.uk/resource/online-behavioural-advertising.html. This Guidance applies to the third parties who collect, analyse and use information for online behavioural advertising ('OBA'), rather than the advertisers themselves, but advertisers will be expected to co-operate with the ASA to identify the relevant third party. Third parties must not target OBA at children aged 12 or under.
As noted above, personalization can have both positive and harmful effects, and risks of the latter are greater when certain factors are present. Given these ambivalent effects, however, where the CMA does choose to intervene, it will:

- do so on the basis of a clear theory of competitive or consumer harm;

- seek to intervene in a way that addresses the harm effectively, but is also proportionate and may take into account risks, including, for example, the potential chilling of pro-competitive business behaviour.

\subsection{The appropriate form of intervention}

The CMA believes that open, competitive markets will typically result in the best outcomes for all consumers, providing innovative products and services, the widest choice and the best value for money. Indeed, as noted above, where there is effective competition, personalized pricing can have positive effects on consumer welfare.

As such, the CMA will typically seek to address the underlying causes of harm. This might include barriers to switching or new entry, or the use of unfair terms or commercial practices, rather than directly regulating the pricing-setting behaviour of businesses. Significantly restricting differentiated pricing could, in the longer term, damage both online traders' and consumers' incentives, rather than benefitting consumers. Where prices are fixed, fewer customers will be likely to compare or switch and those that do would likely put in less effort (as there is less to be gained from doing so), with the effect of reducing the competitive pressure on traders to deliver good value and high quality for consumers. For example, the CMA's energy market investiga$\operatorname{tion}^{23}$ found that the decision by Ofgem - the UK energy regulator - to ban regional price discrimination in 2009 had not had the desired effect of promoting effective competition. Rather, the evidence appeared to suggest that there had in fact been a weakening of competition for the supply of (the costliest) standard variable tariffs which coincided with Ofgem's intervention.

20 CMA Annual Plan 2018 to 2019 (29 March 2018), available at: https://www. gov.uk/government/publications/competition-and-markets-authorityannual-plan-2018-to-2019.

21 For example, following a market study into DCTs using powers under the Enterprise Act 2002, the CMA made recommendations to DCT providers to help online traders comply with the law, but separately opened a competition law investigation into a specific provider: see fn 2 above.

22 CMA Prioritisation Principles (1 April 2014), available at: https://www. gov.uk/government/publications/cma-prioritisation-principles.

23 CMA, Energy market investigation, Final Report (24 June 2016), available at: https://assets.publishing.service.gov.uk/media/5773de34e5274a0da3000113/ final-report-energy-market-investigation.pdf. 
Notwithstanding the above, there may well be circumstances in which, for example:

- there are structural or systemic barriers that will stop markets resolving issues for themselves;

- pro-competitive measures cannot be implemented;

- the nature of the market in question means that benefits of the competitive process may not be delivered to consumers equally or demand-side remedies may not be effective ${ }^{24}$ (including for certain classes of vulnerable consumer, who often face significant barriers in accessing the 'best' deals online).

In such circumstances, alternative forms of (more direct, ex ante) regulation by governments or regulators may be necessary to ensure effective consumer outcomes. Such intervention may take a range of forms, depending on the nature of the market and the potential harm in question.

For example, the Financial Conduct Authority ('FCA'), the UK financial services regulator, has utilized the following broad categorization of interventions seeking to ensure that personalization does not harm consumers: ${ }^{25}$

- Interventions that remove the necessary conditions for price discrimination. In cases where consumers' willingness to pay varies according to either their intrinsic preferences (e.g. risk perception) or their financial position (e.g. income or assets), regulators may be able to do little to affect the variation in willingness to pay between consumer groups. However, there are many cases where differences in willingness to pay are driven by asymmetries between consumers in information, understanding or costs, which can be addressed. For example, where price discrimination is based on differences in consumers' understanding of products, there may be opportunities to help consumers with their decision-making process by improving information disclosure or the provision of advice.

24 For example, in a recent super-complaint to the CMA relating to concerns arising from the 'loyalty penalty' (i.e. that longstanding customers, often on roll-over contracts or default tariffs, pay more for the same services in key markets compared with new customers), Citizens Advice argued that, in 'essential markets' such as telecoms and financial services, the effectiveness of demand-side remedies may be limited by the fact that, among other factors: consumers lack the time to shop around; even if they do, it can be difficult to find a good deal; vulnerable consumers in particular are often unable to access the best deals; the financial cost of switching is often prohibitively high; and consumers are put off taking action by a fear (whether or not legitimate) of things going wrong. On 19 December 2018, the CMA published its response to the Citizens Advice super-complaint: CMA, Tackling the loyalty penalty (19 December 2018), available at: https://assets.publishing.service.gov.uk/ media/5c194665e5274a4685bfbafa/response_to_super_complaint_pdf.pdf. It found that practices by firms exploited customers' loyalty in five markets (cash savings, mortgages, household insurance, mobile phone contracts and broadband) and made recommendations to regulators and government to stop the exploitation of loyal customers. The CMA has also opened a consumer law investigation into the anti-virus software sector, concerning the
- Interventions that reduce the commercial incentives for firms to price discriminate. Online traders price discriminate because it allows them to increase profits relative to a uniform pricing strategy. Interventions that reduce the gains to price discrimination will reduce the incentives to pursue this pricing strategy. In some cases, drawing attention to the practices, highlighting the harm and identifying the worst offenders could act as a sufficient deterrent to online traders. In these instances, the incremental gains from price discrimination are off-set by potential damage to the brand caused by the controversial pricing practice.

- Interventions that put formal constraints on prices (e.g. price caps or uniform pricing requirements). In financial services, direct intervention by restricting the way traders set prices could limit the harmful effects of personalized pricing. This is a straightforward rule that requires firms to charge a single price for all consumers but, furthermore, interventions could apply a relative price cap (e.g. putting limits on differences in prices that firms charge either between different consumer groups or over time) or limit the number of prices they can offer on similar products.

As noted elsewhere in this article, however, there are some risks of unintended consequences. ${ }^{26}$ In this regard, the CMA has recently undertaken work, in conjunction with the FCA, to better understand when and how competition authorities and regulators can intervene to tackle problems arising on the 'demand-side' of markets to best help consumers. This work culminated in a joint CMA/FCA report ${ }^{27}$ which:

- considered the sources of demand-side problems in markets, and in particular the various barriers ${ }^{28}$ that could be created (whether by market characteristics, behavioural biases, or firms' conduct) to the ability of consumers to access, assess and act on information that was vital to the effective functioning of markets;

automatic renewal of subscriptions: see https://www.gov.uk/cma-cases/antivirus-software.

25 Adapted from FCA, Price Discrimination in Financial Services (July 2018), available at: https://www.fca.org.uk/publication/research/price_discrimina tion_in_financial_services.pdf.

26 A theory of harm on the demand side from personalized pricing might, for example, be a consumer's inability to assess value for money (price and quality) because of a combination of dynamic and personalized pricing at play in online markets. This can lead to ineffective competition between service providers and can create barriers to switching.

27 FCA and CMA, Helping people get a better deal: Learning lessons about con sumer facing remedies (October 2018), available at: https://assets.publishing. service.gov.uk/government/uploads/system/uploads/attachment_data/file/ 744521/UKCN_consumer_remedies_project_-_lessons_learned_report.pdf.

28 Those barriers might include, for example, actual or perceived costs to consumers' exercising choice and switching; behavioural or contextual factors (such as vulnerability), which might inhibit consumers' decision making, and suppliers exacerbating the harmful impacts for consumers of these costs/biases. 
- reviewed the effectiveness, which was often mixed, of certain types of remedy ${ }^{29}$ previously used to address such demand-side issues, and how such remedies could be tested, both ex ante - through research, surveys, laboratory tests, field trials, etc. - and ex post;

- set out, based on those insights, some high-level principles for the development of remedies. These include the need to: understand the problem, be bold, let consumers stay in control, consider both real-life behaviour as well as economic analysis, leverage the experience and resources of the private sector, test the effectiveness of remedies, and review that effectiveness ex post.

The CMA has used a five-stage analytical approach to remedy harms during previous consumer enforcement cases (see Annex 3). A consumer enforcement case could be opened, for example, if the harm from personalized pricing was deceiving, misleading or treating consumers unfairly (under the CPR 2008).

\subsection{Intervention: practical challenges and capability building}

As in relation to other commercial conduct in online markets, there are practical challenges for competition and consumer agencies in assessing whether - and if so - when and how to intervene in relation to personalized pricing. Fully investigating potential infringements of the law to the rigorous evidential standards required by UK courts takes time.

In fast-moving and dynamic markets, there is a risk that, by the time an authority has completed its investigation, competitors may have already been forced out of the market, an incumbent's market power may have become further entrenched, or the market may have evolved such that remedies prohibiting the unlawful conduct are ineffective in addressing the competitive concerns in the market. Conversely, there is a risk that hasty interventions may inadvertently serve to chill innovation or further entrench incumbency.

In order to deepen its understanding and expertise of digital markets, and how businesses' use of data impacts competition and consumers, the CMA has established a new Data Technology and Analysis (DaTA) team, comprising data scientists and other technical experts. The CMA sees such capability-building as central to enhancing its ability to identify the most appropriate solution to an identified consumer harm in digital markets.

Helping vulnerable consumers is an extremely important part of the CMA's mission. This is one of the key strategic priorities in its Annual Plan for 2018/1930 and one of the main areas of focus of the government's recent Consumer Green Paper ${ }^{31}$ and draft strategic steer to the CMA. ${ }^{32}$ As part of the CMA's programme of work on consumer vulnerability, we jointly hosted a roundtable discussion with Citizens Advice focused on the challenges and opportunities for vulnerable consumers in relation to data and digital market developments. The summary of this roundtable discussion (and other roundtables covering different dimensions of vulnerability) are published on the CMA's website. ${ }^{33}$

The CMA will support further research into personalized pricing commissioned by the UK government. This research will explore the circumstances where personalized pricing is more prevalent, how businesses are applying it through different mediums like search engines, apps or comparison tools, and the extent to which personalized pricing is preventing shoppers getting the best deals.

This work fits into a broader, coordinated programme of work across the UK government considering competition and consumer welfare in digital markets. This includes, in particular, the establishment of an expert panel, chaired by former US President Barack Obama's chief economic advisor, Professor Jason Furman, to look at competition in the digital economy. ${ }^{34}$
29 Namely, promoting consumer engagement, increasing transparency, helping consumers shop around, facilitating switching and controlling outcomes.

30 CMA Annual Plan 2018 to 2019 (fn 20).

31 Department for Business, Energy and Industrial Strategy, Modernising Consumer Markets, Consumer Green Paper (April 2018), available at: https://assets.publishing.service.gov.uk/government/uploads/system/ uploads/attachment_data/file/699937/modernising-consumer-marketsgreen-paper.pdf.

32 Modernising Consumer Markets (fn 31), Annex A.
33 A summary of the discussion is available at: https://www.gov.uk/government/ publications/vulnerable-consumers.

34 See HM Treasury press release, Former Obama advisor to examine digital competition in the UK (2 August 2018). Other initiatives include the production of a 'Digital Charter' - a rolling programme of work to agree norms and rules for the online world and put them into practice - and the associated establishment of a new Centre for Data Ethics and Innovation. The ethical concerns around personalization, and consumer profiling and targeting more generally, have been identified as potential areas of focus for this Centre. 


\section{Annex 1: Consumer reaction and trader consideration of a personalized pricing offer in the UK}
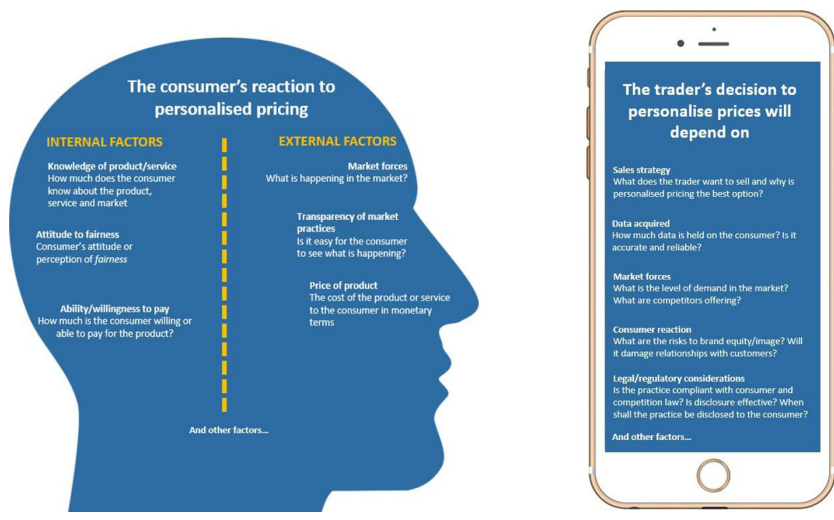

\section{Annex 2: An outline of the Consumer Protection from Unfair Trading Regulations 200835}

1. The CPR 2008 protect consumers from four specific types of practices that are relevant for personalized pricing offers:

(a) commercial practices that are unfair;

(b) commercial practices that are misleading actions;

(c) commercial practices that are misleading omissions;

(d) commercial practices that are aggressive.

2. A commercial practice is unfair if it contravenes the requirements of professional diligence and materially distorts the economic behaviour of the average consumer. Professional diligence means the standard of special skill and care which a trader may reasonably be expected to exercise towards consumers and which is commensurate with either honest market practice in the trader's field of activity or the principle of good faith.

3. A commercial practice is a misleading action if it causes the average consumer to make a transactional decision they otherwise would not have made. Misleading action means the commercial practice contains false or misleading information in relation to: (a) the price or the manner in which the price is calculated;

(b) the existence of a specific price advantage.

4. A misleading omission is a commercial practice that causes the average consumer to make a transaction decision they otherwise would not have made. This might include omitting or hiding material information or providing material information in an ambiguous, unintelligible, unclear or untimely manner. Under law, material information is information an average consumer needs in order to make an informed decision.

5. An aggressive practice is one that significantly impairs, or is likely to significantly impair, the average consumer's freedom of choice through the use of harassment, coercion, or undue influence. When assessing an aggressive practice, the CPR 2008 define a transactional decision as 'any decision taken by a consumer whether it is to act or refrain from acting concerning: (a) whether, how and on what terms to purchase, make payment in whole or in part for, retain or dispose of a product, or (b) whether, how and on what terms to exercise a contractual right in relation to a product'.

6. It is necessary to show that the action of a trader has an effect (or is likely to have an effect) on the actions of the consumer. The test looks at the effect (or likely effect) on the average consumer.

\section{Annex 3: Five-stage analytical framework for a consumer enforcement case}

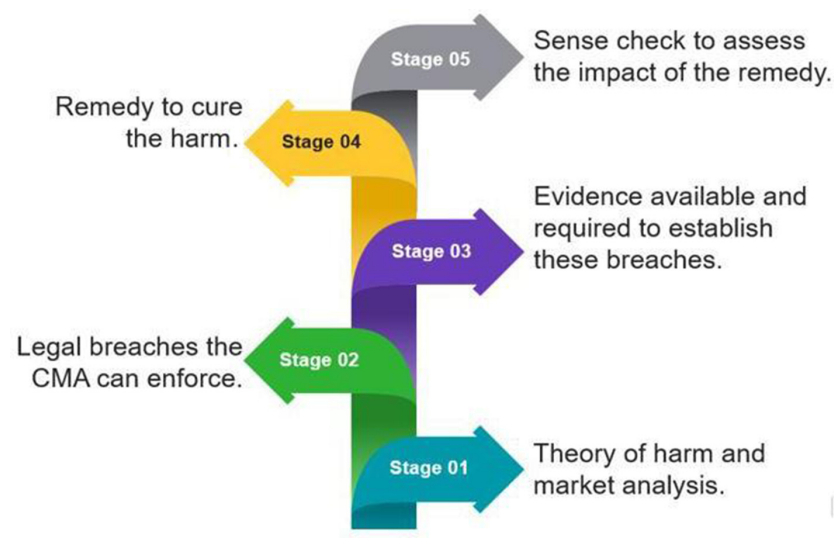

uploads/system/uploads/attachment_data/file/284442/oft1008.pdf, which contains accompanying guidance to the CPR 2008. 


\begin{tabular}{|c|c|}
\hline Stage & Questions to consider \\
\hline $\begin{array}{l}\text { Stage 1: Theory of harm } \\
\text { and market analysis }\end{array}$ & $\begin{array}{l}\text { 1. What is the market in question? What is the problem? } \\
\text { 2. What is the counterfactual to the harm? } \\
\text { 3. How can the harm be dealt with? - is there a remedy? } \\
\text { 4. What consequences will the remedy bring for the market, or other markets? } \\
\text { 5. What would a well-functioning market look like, i.e. can the business operate in a way that } \\
\text { would not be harmful? } \\
\text { 6. In what ways would this market work better for consumers? } \\
\text { 7. What would the market look like without the harm? } \\
\text { 8. Is there an underlying problem, such as lack of competition? } \\
\text { 9. Is there another regime or jurisdictional issues to consider? }\end{array}$ \\
\hline $\begin{array}{l}\text { Stage 2: Identify the legal } \\
\text { breaches, or means by which } \\
\text { the harm can be dealt with }\end{array}$ & $\begin{array}{l}\text { 1. In causing the harm, which laws is the trader infringing? } \\
\text { 2. Who is responsible for these infringements? } \\
\text { 3. Are these laws that the CMA can enforce? } \\
\text { 4. Are the powers available to the CMA suitable to cure the harm? } \\
\text { 5. Would anyone else be better placed to cure the harm? } \\
\text { 6. If bringing criminal action or civil sanctions, have we considered time limits and evidential } \\
\text { rules? }\end{array}$ \\
\hline $\begin{array}{l}\text { Stage 3: Evidential assessment } \\
\text { (how do we prove our case } \\
\text { in court?) }\end{array}$ & $\begin{array}{l}\text { 1. What evidence do we have? } \\
\text { 2. What arguments will the trader run against us/weaknesses in our case? } \\
\text { 3. What further evidence do we need? } \\
\text { 4. How will we get this evidence efficiently and effectively? } \\
\text { 5. Does the quality of evidence we have support all of our arguments? } \\
\text { 6. What is the trader's position? } \\
\text { 7. Is there a need for expert evidence (technical, economic, financial)? } \\
\text { 8. Do we need advice from counsel on the evidence we need? } \\
\text { 9. How will evidence be obtained? } \\
\text { 10. What impact will this have on the timetable? }\end{array}$ \\
\hline
\end{tabular}

Stage 4: Remedy to cure the harm

It is likely that this will be an enforcement action (e.g. intervention or a draft court order). The enforcer must be able to describe what conduct is harmful, and what is not. In the UK:

- Enforcement action should be specific enough that it is clear, without further discussion, what the trader may and may not do.

- Enforcement action must not beg further questions. However, the enforcement action must also be sufficiently comprehensive to prevent future avoidance. It must cure the harm.

- Identify who the enforcement action needs to be against. It should generally be against the company officers unless there are very good reasons only to go against the corporate body.

- Identify the essential points of the enforcement action - what we must get to cure the harm.

Stage 5: Sense check to assess

Analyse whether the enforcement action (e.g. intervention or a draft court order) has dealt with the harm or will cause unintended consequences. This could include:

1. What are the implications of the behaviour changes?

2. Will the firm go out of business?

3. Is it a problem if the firm goes out of business?

4. Will it be better or worse for consumers for the firm to obey the order and stay in business?

5. Will the market remain viable?

6. Will the basis for trading in the market be clear?

7. Will dealing with the named traders cure the harm, or will others in the sector still need to be dealt with?

36 For example, market self-correction, consumer education, information remedy, greater clarity, improved switching, removal of the practice, licensing or barriers to entry, etc. 